\title{
Pattern of Dental Malocclusion in Orthodontic Patients in Erbil City, Kurdistan Region-Iraq, A Retrospective Study
}

\author{
Hasan Sabah Hasan ${ }^{1^{*}}$ and Ayshan Kolemen ${ }^{1}$ \\ ${ }^{1}$ Department of Orthodontics, Khanzad Specialist and Teaching Centre, General Health Directorate in \\ Hawler, Ministry of Health - KRG, Iraq.
}

Authors' contributions

This work was carried out in collaboration between both authors. Both the authors read and approved the final manuscript.

Article Information

DOI: 10.9734/ARRB/2019/v34i430156

Editor(s):

(1) Dr. David E. Martin, Principal and Founder, Martin Pharma Consulting, LLC, Shawnee, OK, USA and Chief Development Officer, Director and Founder, DFH Pharma Inc., Gaithersburg, MD, Maryland, USA.

Reviewers:

(1) Cristina Grippaudo, Catholic University of Sacred Heart, Italy.

(2) Wilson Matsumoto, Brazil.

(3) Chahat Puri, Himachal Pradesh University, India.

(4) K. R. Shilpa Shree, Government Dental College and Hospital, India. Complete Peer review History: http://www.sdiarticle4.com/review-history/54479

Original Research Article

Received 01 December 2019

Accepted 06 February 2020

Published 12 February 2020

\section{ABSTRACT}

Aim: Aims of this study were to assess the pattern of malocclusion in Erbil City, Kurdistan regionIraq.

Methods: A retrospective study includes 1212 patients (589 males and 623 females) that attended orthodontic department at the khanzad polyclinic teaching center / Erbil city, Iraq, aged 11-17 years old with a mean age of $13.49 \pm 1.02$ years that randomly selected. The normal occlusion, malocclusion, overjet, overbite, spacing, crowding, cross bite, midline shifting and midline diastema were examined.

Results: Study demonstrated that $309(25.5 \%)$ of patients had normal occlusion. Class I malocclusion was found in $655(72.5 \%)$, class II was found in $176(19.5 \%)$, and class III malocclusion $72(8.0 \%)$ patients of all examined. Crowding and midline shifting were observed more frequently in females, however, normal bite and posterior open bite were observed more frequently in males and normal crossbite more frequently in both genders. 
Conclusion: Results of this study showed class I molar relationship was the most prevalent type of occlusion in Erbil City, Kurdistan Region-Iraq area and the most prevalent malocclusion was crowded.

Keywords: Pattern; malocclusion; crossbite; overjet; deep bite.

\section{INTRODUCTION}

Malocclusion has been a problem for some individuals. Malocclusion can be defined as the mal relationship between the arches in any plane or a condition characterized by anomalies in tooth position, number, form and developmental position of teeth beyond normal limits [1].

For many years a large number of epidemiological studies have been carried out to determine the pattern of malocclusion in different racial and ethnic groups and the reported incidences variants in different populations [2-5].

Some of these variants were attributed to the differences for specific ethnic groups and also the possible influences of registration methods of malocclusion trait and sample composition [1].

Recently, there has been a dearth of information in the literature on the pattern of malocclusion in Kurdistan region of Iraq.

Study analyzed the prevalence of malocclusion using Angle's classification and occlusal characteristics like overjet, overbite, open bite, spacing and crowding, cross bite, dental midline shifting, midline diastema, among the patients. These occlusal traits are measurable clinical characteristics which help to assess malocclusion and are used by the Dental Health Component of IOTN.

The aim of this study was to:

1. Determine the type of malocclusion,

2. Compare mean ages of the patients in different malocclusion group and

3. Evaluate overjet, overbite, spacing, crowding, crossbite, midline shifting and midline diastema.

\section{MATERIALS AND METHODS}

This retrospective study includes 1212 patients (589 males and 623 females) that attended orthodontic department at khanzad polyclinic teaching center/ General Directorate of hawler/ Ministry of Health/ Kurdistan Regional Government of Iraq, Erbil City, during 2018-2019 years. Aged 11-17 years old with a mean age of $13.49 \pm 1.02$ years (SD), the were randomly selected. The data were obtained through direct clinical examination of the patients by one orthodontist (H.S., author of the article) in the orthodontic department at khanzad polyclinic teaching center utilizing a mouth mirror, check retractor (, wooden spatula and a millimeter ruler with illumination provided by natural day light and dental chair light (Type III examination) as described in World health organization (WHO) Oral Health Survey Basic Methods (1997), [6,7]. Patients themselves and Parents who agreed to have their children examined gave informed consent.

The normal occlusion and malocclusion, overbite, open bite, overjet, spacing, crowding, cross bite, midline shifting, midline diastema pattern of incisors, and the anteroposterior relationships of the maxillary and mandibular first molars in maximum intercuspation according to Angle's classification had been examined in this study.

Various classes of malocclusion according to Angle's classification \& other parameters studied are as described below [8-11].

- Angle's Class I Relation: Mesiobuccal cusp of the maxillary first permanent molar articulates in the mesiobuccal groove of the mandibular first permanent molar.

- Angle's Class II Relation: The mesiobuccal cusp of maxillary first permanent molar articulates mesial to mesiobuccal groove of mandibular first molars.

Angle's Class II, Division I: A class II relation in which maxillary incisors are inclined lovely, and increased overjet is present.

Angle's Class II, Division II: A class II relation in which maxillary central incisors are inclined lingually, and maxillary lateral incisors have tipped labially and mesially, covering the distal of the central incisors. The overjet is reduced, and there is deep 
bite of partial / complete / traumatic / more than $100 \%$ nature.

- Angle's Class III Relation: The mesiobuccal cusp of maxillary first permanent molar occludes distal to mesiobuccal groove of mandibular first molars.

- Overjet: Defined as the horizontal distance between the incisal edge of the most prominent maxillary central incisors to the labial surface of corresponding mandibular central incisors.

- Overbite: Overbite is the vertical relationship of the upper and lower incisors. Measured relative to the incisal ridges.

- Open bite: Anterior was recorded when incisal edges of the maxillary incisors did not overlap the incisal edges of the mandibular incisors. Posterior was recorded when maxillary posterior teeth did not overlap on mandibular teeth.

- Spacing: Spacing was recorded to be present when there was no a proximal contact between 2 teeth in a dental arch.

- Crowding: Crowding was defined as overlapping of erupted teeth due to insufficient space or lack of space for the teeth to erupt in the dental arch.

- Anterior/Posterior Cross Bite: Anterior or posterior cross bite was diagnosed when there was a crossover of at least one tooth in the anterior or posterior region of the dental arch.

- Dental Midline Sifting: Dental midline sifting is shifting from the midsagittal line of maxillary and mandibular dental arches possessing teeth of ideal size, shape, and position, when situated in maximum intercuspation. Each arch also possesses its own midline, which can be used to refer to the location of contact between the mesial surfaces of the central incisors.

- Midline Diastema: Midline diastema is a space between the maxillary and/or mandibular central incisors.

\section{The following selection criteria were used:}

1. The age range of patients between 11-17 years.

2. Patients had no history of previous orthodontic treatment.

3. They had permanent first molars.
4. There are no any systemic diseases, craniofacial deformities and syndromes.

5. All the patients were of Kurdish origin and randomly selected.

\section{The following excluded criteria were used:}

1. Any normal occlusion had been excluded from this study.

2. No quantitative or qualitative measurement for crowding \& spacing was done in any arches. It was just recorded as either present or absent in either of the dental arch. No segregation was done for upper or lower arch.

3. Subdivisions of Angle's class II \& III were not considered during this study.

\subsection{Method of Registration}

1. Sagittal occlusion Angles classification.

2. Overjet: Normal Overjet: 2-3 mm [12], more than $3 \mathrm{~mm}$ is taken as increased and less than $2 \mathrm{~mm}$ was taken as decrease and zero if edge to edge pattern.

3. Over Bite: Normal value 1-2 mm [12] It was considered more if it was increased (deeper) than $2 \mathrm{~mm}$ and decreased if less than $1 \mathrm{~mm}$.

4. Open Bite: Open bite was considered when there were lack of occlusion of the front or posterior teeth when the jaw is closed normally. No overlap between anterior teeth (anterior open bite) and posterior teeth (posterior open bite).

5. Spacing: space between one tooth with respect to another, either in upper or lower dental arch.

6. Crowding: Overlapping of one tooth with respect to another, either in upper or lower dental arch.

7. Crossbite: If one or more maxillary teeth are placed palatal/lingual to the mandibular teeth.

8. Midline Shifting: When the upper midline didn't coincide with lower midline.

9. Midline Diastema: Space of more than 1 $\mathrm{mm}$ between central incisors between either arch.

Data were analyzed using the Statistical Package for Social Sciences (SPSS, version 22). Numerical variables were presented as means and standard deviations. Categorical variables were presented as proportions. Chi square test of association was used to compare the proportions of males and females. The $\mathrm{P}$ 
value of $\leq 0.05$ was considered statistically significant.

\section{RESULTS}

The total number of patients who had been examined at the start of the study was 1212, 309 patients $(25.5 \%)$ had normal occlusion and had been excluded from the study, and the rest (903 patients) had malocclusion. The mean age \pm SD of the studied sample (with malocclusion) was $13.49 \pm 1.02$ years, ranging from 11 to 17 years. The median was 13 years. The highest proportion $(71 \%)$ of the sample fall in the 13-14 year age category, as presented in Table 1 which shows that more than one fifth $(21.3 \%)$ of the females aged $\geq 15$ years compared with $6.5 \%$ of the males $(p<0.001)$. The male: female ratio was $0.90: 1$.

It is evident in Table 2 that $72.5 \%, 19.5 \%$ and $8 \%$ of the sample were of class I, II, and III respectively. Around three quarters (75.3\%) of males and $70 \%$ of females were of class I, while $23.4 \%$ of females and $15.2 \%$ of males were of class II $(p=0.003)$. No significant association was detected between the gender and the divisions of class II type ( $p=$ 0.146).

More than half $(54.9 \%)$ of the sample had normal over jet, $37.6 \%$ had increased over jet, $4.6 \%$ had decreased over jet, and the rest $(2.9 \%)$ had an edge to edge over jet as presented in Table 3 which shows no significant association between gender and over jet $(p=0.080)$.

Half $(50.1 \%)$ of the sample had normal bite, $32.8 \%$ had deep bite and $16.05 \%$ had an open bite as mentioned in Table 4. More males than females had a normal bite $(56 \%$ and $44.9 \%$, respectively) and the differences in the proportions of the bite types were significant $(p=$ $0.005)$. Regarding the open bite types, the table shows that the majority $(74.2 \%)$ of the males had posterior open bite type, compared with $43.4 \%$ of the females $(p<0.001)$.

Table 5 shows that no spacing between the teeth was detected in $79.1 \%$ of the sample, and the differences in the prevalence of spacing didn't differ significantly between males and females ( $p$ $=0.973$ ). The prevalence of crowding was $47 \%$ among females, which was significantly higher than the prevalence $(40.1 \%)$ among males $(p=$ 0.035).

The majority $(81.1 \%)$ of the sample had normal cross-bite as presented in Table 6. No significant association was detected between the cross-bite and gender $(p=0.327)$. The type of posterior cross-bite was unilateral in $15.8 \%$ of females and $6.6 \%$ of males $(p=0.094)$.

Table 1. Age distribution of the studied sample by gender

\begin{tabular}{llllllll}
\hline \multirow{2}{*}{$\begin{array}{c}\text { Age } \\
\text { (years) }\end{array}$} & \multicolumn{2}{c}{ Male } & \multicolumn{2}{c}{ Female } & \multicolumn{2}{c}{ Total } & P \\
\cline { 2 - 7 } & No. & $(\%)$ & No. & $(\%)$ & No. & $(\%)$ & \\
\hline $11-12$ & 104 & $(24.2)$ & 29 & $(6.1)$ & 133 & $(14.7)$ & \\
$13-14$ & 297 & $(69.2)$ & 344 & $(72.6)$ & 641 & $(71.0)$ & \\
$\geq 15$ & 28 & $(6.5)$ & 101 & $(21.3)$ & 129 & $(14.3)$ & $<0.001$ \\
\hline Total & 429 & $(100.0)$ & 474 & $(100.0)$ & 903 & $(100.0)$ & \\
\hline
\end{tabular}

Table 2. Malocclusion and its types of gender

\begin{tabular}{llllllll}
\hline & \multicolumn{2}{c}{ Male } & \multicolumn{2}{c}{ Female } & \multicolumn{2}{c}{ Total } & P \\
\cline { 2 - 7 } & No. & $\mathbf{( \% )}$ & No. & $\mathbf{( \% )}$ & No. & (\%) & \\
\hline Malocclusion & & & & & & & \\
\hline Class I & 323 & $(75.3)$ & 332 & $(70.0)$ & 655 & $(72.5)$ & \\
Class II & 65 & $(15.2)$ & 111 & $(23.4)$ & 176 & $(19.5)$ & \\
Class III & 41 & $(9.6)$ & 31 & $(6.5)$ & 72 & $(8.0)$ & 0.003 \\
\hline Total & 429 & $(100.0)$ & 474 & $(100.0)$ & 903 & $(100.0)$ & \\
\hline Class II types & & & & & & & \\
\hline Div. I & 49 & $(75.4)$ & 72 & $(64.9)$ & 121 & $(68.8)$ & \\
Div. II & 16 & $(24.6)$ & 39 & $(35.1)$ & 55 & $(31.3)$ & 0.146 \\
\hline Total & 65 & $(100.0)$ & 111 & $(100.0)$ & 176 & $(100.0)$ & \\
\hline
\end{tabular}


Midline shifting was present in $36.5 \%$ of the whole sample, but it was significantly $(p=0.003)$ higher among females $(41.1 \%)$ than among males $(31.5 \%)$. No significant association was detected between gender and diastema ( $p=$ $0.064)$ although it was higher among males than females $(8.6 \%$ and $5.5 \%$ respectively).

\section{DISCUSSION}

Aim of this study was to Determine the type of malocclusion, compare mean ages of the patients in different malocclusion group and to evaluate overjet, overbite, spacing and crowding, crossbite, midline shifting and midline diastema, and, their ages ranged from 11 to 17 years; this is the preferred age range for orthodontic treatment.

In this study, The mean age \pm SD of the studied sample (with malocclusion) was 13.49+1.02 years $(71 \%)$, this is the preferred age range for orthodontic intervention if malocclusion is found because it is the stage of late-mixed or earlypermanent dentition, which was higher comparable to that in American Latinos (6.5\%) [13], Gardner [14] (3\%), Bugaighis et al. [15] (4.7\%), white Americans (35\%), [16], Egyptians (34.33\%), [17], Northern Nigeria (12\%) [18], Begin city [19] and then Nigeria (15\%), [20]. The pattern of malocclusion came out quite high and the most predominant was class I malocclusion $(72.5 \%)$, was higher than found in Americans (55\%), [16] and comparatively less than that reported by Gardner (74\%), [14] and Bugaighis et al. (66.5\%), [15].

Class II malocclusion in the current study $(19.5 \%)$ in division I (68.8\%) and in division II $(31.3 \%)$, was significant differences between male and female, but no significant association was detected between the gender and the

Table 3. Types of over jet by gender

\begin{tabular}{llllllll}
\hline \multirow{2}{*}{ Over jet } & \multicolumn{2}{c}{ Male } & \multicolumn{2}{c}{ Female } & \multicolumn{2}{c}{ Total } & P \\
\cline { 2 - 7 } & No. & $(\%)$ & No. & $(\%)$ & No. & $(\%)$ & \\
\hline Normal & 240 & $(55.9)$ & 261 & $(55.06)$ & 501 & $(55.47)$ & \\
Increase & 148 & $(35.0)$ & 187 & $(40.0)$ & 335 & $(37.09)$ & \\
Decrease & 26 & $(6.1)$ & 15 & $(3.2)$ & 41 & $(4.54)$ & \\
Edge to edge & 15 & $(3.5)$ & 11 & $(2.4)$ & 26 & $(2.9)$ & 0.080 \\
\hline Total & 429 & $(100.0)$ & 474 & $(100.0)$ & 903 & $(100.0)$ & \\
\hline
\end{tabular}

Table 4. Types of bite by gender

\begin{tabular}{llllllll}
\hline & \multicolumn{2}{c}{ Male } & \multicolumn{2}{c}{ Female } & \multicolumn{2}{c}{ Total } & P \\
\cline { 2 - 7 } & No. & $\mathbf{( \% )}$ & No. & $\mathbf{( \% )}$ & No. & $\mathbf{( \% )}$ & \\
\hline Bite & & & & & & & \\
\hline Normal & 259 & $(59.67)$ & 220 & $(46.90)$ & 479 & $(53.05)$ & \\
Deep & 113 & $(28.4)$ & 166 & $(36.7)$ & 279 & $(30.9)$ & \\
Open & 62 & $(15.6)$ & 83 & $(18.4)$ & 145 & $(16.05)$ & 0.005 \\
\hline Total & 434 & $(100.0)$ & 469 & $(100.0)$ & 903 & $(100.0)$ & \\
\hline Open bite type & & & & & & \\
\hline Anterior & 16 & $(25.8)$ & 47 & $(56.6)$ & 63 & $(43.4)$ & \\
Posterior & 46 & $(74.2)$ & 36 & $(43.4)$ & 82 & $(56.6)$ & $<0.001$ \\
\hline Total & 62 & $(100.0)$ & 83 & $(100.0)$ & 145 & $(100.0)$ & \\
\hline
\end{tabular}

Table 5. Prevalence of space and crowding by gender

\begin{tabular}{llllllll}
\hline & \multicolumn{2}{c}{ Male } & \multicolumn{2}{c}{ Female } & \multicolumn{2}{c}{ Total } & P \\
\cline { 2 - 7 } & No. & $(\%)$ & No. & (\%) & No. & (\%) & \\
\hline Spacing & & & & & & & \\
\hline Yes & 90 & $(21.0)$ & 99 & $(20.9)$ & 189 & $(20.9)$ & \\
No & 339 & $(79.0)$ & 375 & $(79.1)$ & 714 & $(79.1)$ & 0.973 \\
\hline \multicolumn{2}{l}{ Crowding } & & & & & & \\
\hline Yes & 172 & $(40.1)$ & 223 & $(47.0)$ & 395 & $(43.7)$ & \multirow{2}{*}{0.035} \\
No & 257 & $(59.9)$ & 251 & $(53.0)$ & 508 & $(56.3)$ & \\
\hline Total & 429 & $(100.0)$ & 474 & $100.0)$ & 903 & $(100.0)$ & \\
\hline
\end{tabular}


Table 6. The types of cross-bite by gender

\begin{tabular}{|c|c|c|c|c|c|c|c|}
\hline & \multicolumn{2}{|c|}{ Male } & \multicolumn{2}{|c|}{ Female } & \multicolumn{2}{|c|}{ Total } & \multirow[t]{2}{*}{$\mathbf{P}$} \\
\hline & No. & (\%) & No. & $(\%)$ & No. & (\%) & \\
\hline \multicolumn{8}{|c|}{ Cross-bite } \\
\hline Normal & 348 & $(81.1)$ & 384 & $(81.0)$ & 732 & $(81.1)$ & \\
\hline Anterior & 20 & $(4.7)$ & 14 & $(3.0)$ & 34 & $(3.8)$ & \\
\hline Posterior & 61 & (14.2) & 76 & (16.0) & 137 & (15.2) & 0.327 \\
\hline Total & 429 & $(100.0)$ & 474 & $(100.0)$ & 903 & $(100.0)$ & \\
\hline \multicolumn{8}{|c|}{ Posterior cross-bite } \\
\hline Unilateral & 4 & (6.6) & 12 & (15.8) & 16 & (11.7) & \\
\hline Bilateral & 57 & (93.4) & 64 & (84.2) & 121 & (88.3) & 0.094 \\
\hline Total & 61 & $(100.0)$ & 76 & $(100.0)$ & 137 & $(100.0)$ & \\
\hline
\end{tabular}

Table 7. Prevalence of midline shifting and diastema by gender

\begin{tabular}{llllllll}
\hline & \multicolumn{2}{c}{ Male } & \multicolumn{2}{c}{ Female } & \multicolumn{2}{c}{ Total } & P \\
\cline { 2 - 7 } & No. & $(\%)$ & No. & $(\%)$ & No. & (\%) & \\
\hline \multicolumn{2}{l}{ Midline shifting } & & & & & & \\
\hline Yes & 135 & $(31.5)$ & 195 & $(41.1)$ & 330 & $(36.5)$ & \\
No & 294 & $(68.5)$ & 279 & $(58.9)$ & 573 & $(63.5)$ & 0.003 \\
\hline Diastema & & & & & & & \\
\hline Yes & 37 & $(8.6)$ & 26 & $(5.5)$ & 63 & $(7.0)$ & \\
No & 392 & $(91.4)$ & 448 & $(94.5)$ & 840 & $(93.0)$ & 0.064 \\
\hline Total & 429 & $(100.0)$ & 474 & $(100.0)$ & 903 & $(100.0)$ & \\
\hline
\end{tabular}

divisions of class II type, comparable to, Bugaighis et al. [15]. Was less observation $(25.4 \%)$ in division I and (3.5\%) in division II and to Gardner's $(18 \%$ in division I and $2 \%$ in division II), [14].

The incidence of class III malocclusion (8.0\%) in the present study, came out to be near to that found in Egyptian (10.6\%) but higher to that found in Danish (4.3\%), and British subjects $(2.9 \%),[17,21,22]$.

Overjet in this study was found to be normal (2 $\mathrm{mm}$ ) in $55.47 \%$. Excessive (> $3 \mathrm{~mm}$ ) in $37.09 \%$ and reduced in $(4.54 \%)$ and edge to edge in $(2.9 \%)$, without any significant gender difference $(p>0.080)$. These findings were different to those observed by Proffit et al. [16] who reported $29.6 \%$ had normal and $(45.2 \%)$ had increased overjet with significant gender difference, but was similar to that findings by Gelgor et al. [23] ( $p<$ $0.05)$, and less than findings in Riyadh $(75.4 \%)$ with reduced overjet $(<2 \mathrm{~mm})(19.3 \%)$, which is more than that found in the northern border region of Saudi Arabia (11.4\%). An increased overjet (> $3 \mathrm{~mm}$ ) was found in $(37 \%)$, which was higher in comparison to the findings in Jordan $(24.7 \%)$ and less to that in Turkey $(41.7 \%)$ [24$27]$. The prevalence of edge-to-edge was (4.5\%), which is less than that observed in Turkey $(12.1 \%)$ [27].
We found that $(53.05 \%)$ of the study subjects had a normal overbite, the differences in the proportions of the bite types were significant $(p=$ $0.005)$. Which is less comparable to the findings in the northern border region of Saudi Arabia $(64.4 \%)$ and similar to that in Turkey $(53.5 \%)$ $[25,27]$.

A deep bite was found in $(32.8 \%)$, which is higher than the $(1.7 \%)$ found in Kuwait [26], in Riyadh (8.8\%) [28], in Turkish population $(7 \%)$ [29] and black Americans (10\%) [30].

An open bite was found in $(16.05 \%)$, which is higher to the northern border region of Saudi Arabia $(4.6 \%)$ and to that in Colombia $(9 \%)$ [31,32].

Spacing problems were found in $(20.9 \%)$ in this study; which was similar to that finding in Riyadh $(20.4 \%)$, more of that in Asser (16.7\%), Turkey $(12.5 \%)$, less than found in the northern border region of Saudi Arabia (27.2\%), Jordan (26.7\%), and Colombia (25.9\%) [33,34,35,36-38].

Crowding was recorded in $(43.7 \%)$ of the examined subjects, while in the northern border region of Saudi Arabia, Riyadh, and Aseer, it was much more prevalent $(47.2 \%, 45.4 \%$, and $43.8 \%$, respectively) [33-39]. The result being less to that found by Kaur et al. in south Indian population 
(57.69\%) and of Lauc. T in Hvar Island, Coroatia $(57.1 \%)$ but much more than that found in Ibadan, Nigeria (20\%) [37,40].

Anterior crossbite was observed in (3.8\%), less than found by $\mathrm{H}$. Kaur in south Indian population $(8.46 \%)$, but near similar to that discovered by Rajendra et al, in Nalgoda school children $(4.75 \%) \quad[17,37]$. Posterior crossbite was recorded at $15.2 \%$, which was more than found in a Rajendra et al. study $(3.75 \%)$, but much less than found in Rio de Janeiro State, Brazil $(19.2 \%)$, and in Lahore, Pakistan (24\%) [17,18, $37,38]$.

Bilateral crossbite had been the most frequently observed pattern of crossbite (88.3\%). With no gender difference. Unilateral cross bite, there was a gender difference between female and male. High rates of crossbite might be that our study evaluated the subjects accepted for orthodontic treatment but, Gelgor et al. Investigated the referred population. The difference might be due to the material difference $[23,24,41]$.

Midline shifting was $(36.5 \%)$ in examining samples, but it was significantly $(p=0.003)$ higher among females $(41.1 \%)$ than among males $(31.5 \%)$. They came out was less than found in Lebanese $(46.83 \%)$ [42,43,44,45].

The prevalence of maxillary midline diastema $(7 \%)$, in the present study, was higher than finding by Thilander et al. (4.0\%) and Turkey $(4.5 \%)$, but similar to that reported by Gelgor et al. (7.0\%), Colombia (7\%) and very close to that found in Jordan (6.9\%) $[2,23,35]$.

\section{CONCLUSION}

- In a sample of orthodontically referred erbil city, Kurdistan Region-Iraq area population, class I have been the most frequently seen malocclusion, whereas class III was the least common.

- Crossbite was the most common finding in both genders.

- Normal bite and posterior open bite was more common in male.

- Crowding and midline shifting was more common in female.

\section{CONSENT}

As per international standard or university standard written parents consent has been collected and preserved by the author(s).

\section{ETHICAL APPROVAL}

As per international standard or university standard written ethical approval has been collected and preserved by the author(s).

\section{COMPETING INTERESTS}

Authors have declared that no competing interests exist.

\section{REFERENCES}

1. Gardiner JH. An orthodontic survey of Libyan schoolchildren. British Journal of Orthodontics. 1982;9(1):59-61.

Available:https://doi.org/10.1179/bjo.9.1.59

2. Thilander B, Pena L, Infante C, Parada SS, de Mayorga C. Prevalence of malocclusion and orthodontic treatment need in children and adolescents in Bogota, Colombia. An epidemiological study related to different stages of dental development. European Journal of Orthodontics. 2001;23(2):153-68.

3. Brunelle JA, Bhat $M$, Lipton JA. Prevalence and distribution of selected occlusal characteristics in the US population, 1988-1991. Journal of Dental Research. 1996;75(2_suppl):706-13.

Available:https://doi.org/10.1177/00220345 9607502 S10

4. Fabio Ciuffolo, Lamberto Manzoli, Michele D'Attilio, Simona Tecco, Filippo Muratore, Felice Festa, Ferdinando Romano, Prevalence and distribution by gender of occlusal characteristics in a sample of Italian secondary school students: A crosssectional study. European Journal of Orthodontics. 2005;27(6):601-606.

Available:https://doi.org/10.1093/ejo/cji043.

5. Josefsson $\mathrm{E}$, Bjerklin $\mathrm{K}$, Lindsten $\mathrm{R}$. Malocclusion frequency in Swedish and immigrant adolescents-influence of origin on orthodontic treatment need. The European Journal of Orthodontics. 2007; 29(1):79-87.

6. Abu Alhaija ES, Al-Nimri KS, Al-Khateeb SN. Self-perception of malocclusion among north Jordanian school children. The European Journal of Orthodontics. 2005;27(3):292-5.

7. Kumar DA, Varghese RK, Chaturvedi SS, Agrawal A, Fating C, Makkad RS. Prevalence of malocclusion among children and adolescents residing in 
orphanages of Bilaspur, Chattishgarh, India. Journal of Advanced Oral Research. 2012;3(3):18-23.

8. Moyers RE. Handbook of orthodontics $4^{\text {th }}$ Ed. London: Year Book Medical Publisher.

9. Sandeep G, Sonia G. Pattern of dental malocclusion in orthodontic patients in Rwanda: A retrospective hospital based study. Rwanda Medical Journal. 2012; 69(4):13-8.

10. Kamath MK, Arun AV. Midline diastema. International Journal of Orthodontic Rehabilitation. 2016;7(3):101.

11. Nelson SJ. Wheeler's Dental Anatomy, Physiology and Occlusion-E-Book. Elsevier Health Sciences; 2014.

12. Proffit WR, Fields HW, Sarver DM. Contemporary orthodontics-e-book. Elsevier Health Sciences; 2014.

13. Silva RG, Kang DS. Prevalence of malocclusion among Latino adolescents. American Journal of Orthodontics and Dentofacial Orthopedics. 2001;119(3): 313-5.

14. Gardiner JH. An orthodontic survey of Libyan schoolchildren. $\mathrm{Br} \mathrm{J}$ Orthod. 1982;9:59-61. [PubMed] [Google Scholar].

15. Bugaighis I, Karanth D. The prevalence of malocclusion in urban Libyan school children. Journal of Orthodontic Science. 2013;2(1):1.

16. Proffit WR, Fields JH, Moray LJ. Prevalence of malocclusion and orthodontic treatment need in the United States: estimates from the NHANES III survey. The International Journal of Adult Orthodontics and Orthognathic Surgery. 1998; 13(2):97-106.

17. El-Mangoury NH, Mostafa YA. Epidemiologic panorama of dental occlusion. Angle Orthod. 1990;60(3):207-14.

18. Borzabadi-Farahani A, Borzabadi-Farahani A, Eslamipour F. Malocclusion and occlusal traits in an urban Iranian population. An epidemiological study of 11to 14-year-old children. The European Journal of Orthodontics. 2009;31(5):47784.

19. Dacosta OO. The prevalence of malocclusion among a population of northern Nigeria school children. West African Journal of Medicine. 1999;18(2): 91-6.

20. Ajayi EO. Prevalence of malocclusion among school children in Benin City, Nigeria. Journal of Medicine and Biomedical Research. 2008;7(1-2).
21. Helm S. Malocclusion in Danish children with adolescent dentition: An epidemiological study. American Journal of Orthodontics. 1968;54(5):352-66.

22. Clare R. Orthodontics and the school child: a survey of 680 children. British Dental Journal. 1944;79:278-80.

23. Gelgör İE, Karaman Aì, Ercan E. Prevalence of malocclusion among adolescents in central Anatolia. European Journal of Dentistry. 2007;1(3):125.

24. Abu Alhaija ES, Al-Khateeb SN, Al-Nimri KS. Prevalence of malocclusion in 13-15 year-old North Jordanian school children. Community Dent Health. 2005;22(4):26671.

25. Gudipaneni RK, Aldahmeshi RF, Patil SR, Alam MK. The prevalence of malocclusion and the need for orthodontic treatment among adolescents in the northern border region of Saudi Arabia: An epidemiological study. BMC Oral Health. 2018;18:16.

PMID: 29390986 PMCID:PMC5796577. Available:https://doi.org/10.1186/s12903018-0476-8

26. Albakri, Fahad, Ingle, Navin, Assery, Mansour. Prevalence of Malocclusion among Male School Childrenin Riyadh City. Open Access Macedonian Journal of Medical Sciences. 2018;6:1296.

DOI: 10.3889/oamjms.2018.207

27. Celikoglu M, Akpinar S, Yavuz I. The pattern of malocclusion in a sample of orthodontic patients from Turkey. Med Oral Patol Oral Cir Bucal. 2010;15:e791-e796.

28. Gudipaneni RK, Aldahmeshi RF, Patil SR, Alam MK. The prevalence of malocclusion and the need for orthodontic treatment among adolescents in the northern border region of Saudi Arabia: An epidemiological study. BMC Oral Health. 2018;18:16.

29. Meer Z, Sadatullah S, Wahab MA, Mustafa AB, Odusanya SA, Razak PA. Prevalence of malocclusion and its common traits in Saudi males of Aseer region. Journal of Dental Research and Review. 2016;3(3): 99.

30. Gudipaneni RK, Aldahmeshi RF, Patil SR, Alam MK. The prevalence of malocclusion and the need for orthodontic treatment among adolescents in the northern border region of Saudi Arabia: An epidemiological study. BMC Oral Health 2018;18:16.

31. Baum AT. The midline diastema. J Oral Med. 1966;21:30-9.

PMID:4951230. 
32. Adib K, Joseph BS, Nayla BN. Orthodontic patients: An epidemiologic and analytic study, an observational retrospective study. International Arab Journal of Dentistry. 2010;1:36-43.

33. Abu Alhaija ES, Al-Khateeb SN, Al-Nimri KS. Prevalence of malocclusion in 13-15 year-old North Jordanian school children. Community Dent Health. 2005;22(4):26671.

34. Albakri FM, Ingle N, Assery MK. Prevalence of Malocclusion among Male School Children in Riyadh City. Open access Macedonian Journal of Medical Sciences. 2018;6(7):1296.

35. American Dental Association: Adopted 1995, Revised 1997. (N.d.).

Available:https://www.ada.org/en/memberc enter/member-benefits/practiceresources/dental-practiceparameters/ malocclusion

36. Onyeaso CO. Prevalence of malocclusion among adolescents in Ibadan, Nigeria. Am J Orthod Dentofacial Orthop. 2004; 126(5):604-7.

37. Kaur H, Pavithra US, Abraham R. Prevalence of malocclusion among adolescents in South Indian population. J Int Soc Prev Community Dent 2013;3(2): 97-102.

38. Reddy ER, Manjula M, Sreelakshmi N, Rani ST, Aduri R, Patil BD. Prevalence of malocclusion among 6 to 10 year old Nalgonda school children. Journal of International Oral Health: JIOH. 2013;5(6): 49.
39. Celikoglu M, Akpinar S, Yavuz I. The pattern of malocclusion in a sample of orthodontic patients from Turkey. Med Oral Patol Oral Cir Bucal. 2010;15(5):e791-6. Available:http://www.medicinaoral.com/me doralfree01/v15i5/medoralv15i5p791.pdf

40. Llompart G, Marín GH, Silberman M, Merlo I, Zurriaga $O$. Oral health in 6-year-old schoolchildren from Berisso, Argentina: Falling far short of WHO goals. Medicina Oral, Patologia Oral Y Cirugia Bucal. 2010;15.

41. Kassis A, Serhal JB, Bassil-Nassif N. Malocclusion in Lebanese orthodontic patients: An epidemiologic and analytic study. International Arab Journal of Dentistry. 2010;1(1).

42. Behbehani F, Årtun J, Al-Jame B, Kerosuo $\mathrm{H}$. Prevalence and severity of malocclusion in adolescent Kuwaitis. Medical Principles and Practice. 2005; 14(6):390-5.

43. Demir A, Uysal T, Basciftci FA, Guray E. The association of occlusal factors with masticatory muscle tenderness in 10-to 19-year old Turkish subjects. The Angle Orthodontist. 2005;75(1):40-6.

44. Asiry MA. Occlusal status among 12-16 year-old school children in Riyadh, Saudi Arabia. Journal of International Oral Health: JIOH. 2015;7(5):20.

45. Lauc T. Orofacial analysis on the Adriatic islands: An epidemiological study of malocclusions on Hvar Island. The European Journal of Orthodontics. 2003; 25(3):273-8.

(C) 2019 Hasan and Kolemen; This is an Open Access article distributed under the terms of the Creative Commons Attribution License (http://creativecommons.org/licenses/by/4.0), which permits unrestricted use, distribution, and reproduction in any medium, provided the original work is properly cited.

Peer-review history:

The peer review history for this paper can be accessed here: http://www.sdiarticle4.com/review-history/54479 